\title{
Comparison of the accuracy of a free 3D camera system with the Ariel performance system
}

Paulo Miranda-Oliveira, Marco Branco, Orlando J. Fernandes \& Rita SantosRocha

To cite this article: Paulo Miranda-Oliveira, Marco Branco, Orlando J. Fernandes \& Rita SantosRocha (2021): Comparison of the accuracy of a free 3D camera system with the Ariel performance system, Computer Methods in Biomechanics and Biomedical Engineering: Imaging \& Visualization, DOI: $10.1080 / 21681163.2021 .1931963$

To link to this article: https://doi.org/10.1080/21681163.2021.1931963

曲 Published online: 09 Jun 2021.

Submit your article to this journal $\longleftarrow$

山 Article views: 33

Q View related articles $\sqsubset$

View Crossmark data ¿ 


\title{
Comparison of the accuracy of a free 3D camera system with the Ariel performance system
}

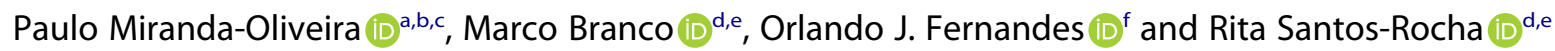

aFederação Portuguesa de Atletismo, Oeiras, Portugal; 'baboratório de Investigação em Desporto e Saúde (Unidade de Fisiologia e Biomecânica do Desporto), Escola Superior de Desporto de Rio Maior, Instituto Politécnico de Santarém, Portugal; 'Escola Superior de Tecnologia e Gestão, Instituto Politécnico de Leiria, Leiria, Portugal; ' ${ }^{E}$ scola Superior de Desporto de Rio Maior, Instituto Politécnico de Santarém, Portugal; ${ }^{e} \mathrm{CIPER}$, Faculdade de Motricidade Humana, Universidade de Lisboa, Cruz Quebrada Dafundo, Portugal; ${ }^{\text {fC}}$ Comprehensive Health Research Center (CHRC), Departamento de Saúde e Desporto, Universidade de Évora, Portugal

ABSTRACT

The aims were: (1) to determine the accuracy and time-consuming of the automatic digitalization feature of 3D motion analysis systems; and (2) to determine the reliability of the 3D position when a football player performed a hard kick with spin. Four high-speed cameras (Casio ZR200 (512×384)) with a $240 \mathrm{~Hz}$ field rate were used. Automatic scanning of the Kinovea ${ }^{\circledR}$ and APAS $^{\circledR}$ software was used. The accuracy was determined through mean absolute error, maximum absolute error, mean standard deviation of absolute error, and the variability values. The reliability was calculated with the Intra-Class Correlation. The mean absolute error ( 3.62 to $3.78 \mathrm{~mm}$ ), maximum absolute error ( 9.09 to $11.61 \mathrm{~mm}$ ), mean standard deviation of absolute error $(0.01$ to $0.59 \mathrm{~mm})$, variability values $(<1 \mathrm{~mm})$, and the auto-digitalization time (16 to 31 minutes) were calculated and were within the values obtained in the literature. The reliability was determined with the Intra-Class Correlation, and the results were higher than 0.90, warrantied a high consistency for chosen software. The accuracy and the reliability intra-operator were determined, and the results indicated that it is possible to apply the free 3D camera system, with consistency in free-kick analysis.
ARTICLE HISTORY

Received 17 August 2020

Accepted 16 May 2021

\section{KEYWORDS}

Accuracy; reliability and motion analysis system

\section{Introduction}

Many software that performs human motion three-dimensional analysis are marketed and have similar features. The difference between them is the price, the accuracy and the consistency, and the characteristics associated with it (Ehara et al. 1995, 1997).

The accuracy, referenced to most of the literature, is determined by the statistical parameters, such as absolute error, maximum absolute error, median, square root, coefficient of variation, and the time (Klein and DeHaven 1995; Ehara et al. 1995, 1997; Richards 1999; Papic et al. 2004; Chiari et al. 2005; Wilson et al. 2012; Robertson et al. 2014).

The reliability is the characteristic that determines the observed value when the evaluation is repeated (Hopkins 2000) and may calculate the degree of agreement between sets of observational data collected independently from the same scene by two different observers (inter-observer agreement) or by the same observer (intra-observer agreement) (Jansen et al. 2003). The literature indicated the statistical tests, such as the correlation tests to determine the reliability (Scholz 1989; Brosseau et al. 1997; Keeley et al. 2011; Serrano and Fernandes 2011).

Vander Linden et al. (1992) suggested that determining the accuracy parameters of the motion analysis systems should be performed before the data collection. Klein and DeHaven (1995) indicated that the determination of the error of the motion analysis systems is possible to quantify. The error obtained through the accuracy may create new applications, such as calibration volume smallest or new filters or smoothing to solve problems as the phenomenon of lens distortion (Chiari et al. 2005). The technology has evolved, the motion analysis systems have new features, and further research proposals have emerged, such as the calculation of the error and the time associated with these new features (Klein and DeHaven 1995; Richards 1999; Wilson et al. 1999).

Ehara et al. (1997) indicated the importance of the error calculation of these motion analysis systems, during the human walking task, in healthy people. The determination of the error for each system, each task, and/or each environment is suggested because it is expected that the error results are different for each constraint. So, these results can help to select an appropriate motion analysis system and to quantify the associated error. Brosseau et al. (1997) and Serrano and Fernandes (2011) determined the reliability in a physiotherapy instrument and in a video analysis system, respectively. These authors suggested the possibility of using these instruments without changing the accuracy and consistency in the different analyses. To study the accuracy and consistency in the Kinovea ${ }^{\circledR}$ system with Scilab $^{\circledR}$ routines is necessary. Therefore, the purpose was (1) to determine the accuracy and the timeconsuming of the automatic digitalization feature of 3D motion analysis systems, and (2) to determine the reliability of the 3D 
position in Kinovea ${ }^{\circledR}$ system with Scilab $^{\circledR}$ routines, when a football player performed a hard kick with spin.

\section{Methods}

The present work consisted of cross-sectional analysis, in which it was intended to analyze the accuracy and time-consuming of two 3D motion analysis systems, as well as to analyse its consistency regarding a common soccer motor task (i.e. hard kick with spin). The same instruments, distances between the cameras, and calibration volume were considered.

\section{Instrumentation}

\section{Systems tested}

The systems tested were the Kinovea ${ }^{\circledR}$ system with Scilab ${ }^{\circledR}$ routines (Software 1, free software) and the Ariel APAS ${ }^{\circledR}$ (Ariel Dynamic) (Software 2). As the Kinovea ${ }^{\circledR}$ system is a bidimensional software, so extracting bi-dimensional coordinates (XY) for each camera, so the Scilab routines were used to convert these bi-dimensional coordinates into threedimensional coordinates (XYZ), through the threedimensional direct linear transformation method (3DDLT) (Abdel-Aziz et al. 2015). The Ariel APAS ${ }^{\circledR}$ software was considered for this study because it is one of the most used motion analysis systems in the kinematic analysis, and it is used only as a reference for validity.

\section{Material used}

To capture the volume and the free-kick motion, four highspeed (HS) cameras, Casio ZR200 (512×384), with a capture rate of $240 \mathrm{~Hz}$, were used. The white light markers (diameter $=1 \mathrm{~cm}$ and height $=1.5 \mathrm{~cm}$ ), developed in the university laboratory, were used to ensure the automatic characteristic better. Also, it was used a measuring tape to measure the real coordinates of the calibration volume.

\section{Procedures}

\section{Determine the accuracy}

The accuracy was performed in the laboratory, following the experimental design presented in Figure 1(a), considering the calibration volume (Figure 1(b)). The same structure (Figure 1 (b)) was used to determine the accuracy parameters. The light markers were placed in each calibration point with a tape, and all points were viewed by all cameras. The real coordinate value was considered (Table 1) to compare with the values obtained through the motion analysis systems (Figure 2). For both motion analysis systems, all points were digitalized, and the analysis was performed twice (test 1 and test 2).

\section{Determine the reliability}

The reliability of the automatic digitalization of the motion analysis system was determined during the execution of a hard kick with spin performed by a professional football player. This motor task was carried out in the field. The environment for task execution had a goalkeeper and an artificial barrier with five static mannequins. The football player was instructed to make a goal. It was used an experimental design (Figure 3(a)), and the calibration volume showed in Figure 3 (b) $(141.5 \times 198 \times 283 \mathrm{~cm})$. The biomechanical model was applied according to De Leva (1996), and the landmarks were fixed with Velcro tape to ensure a good holder (Figure 4).

The football player was tested, and the initial criterion was five frames before the ball contact of the dominant foot in the last stride, and the final criterion was five frames after the foot contact with the ball.

The protocol used to determine the reliability was: (1) the calibration volume was placed to cover the two last steps before the kick on the ball; (2) the calibration volume was recorded; (3) the subject was prepared with the landmarks and (4) the athlete performed the task.

b)

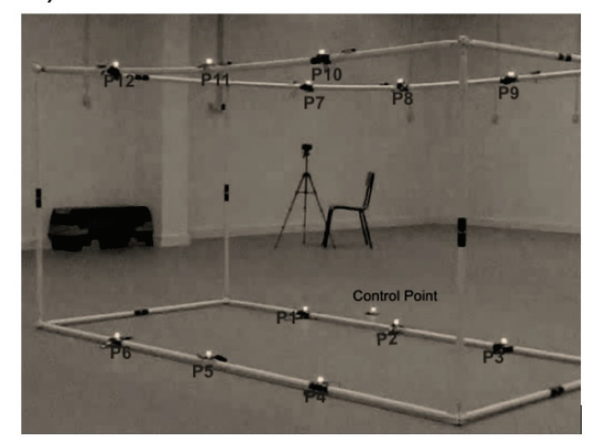

Figure 1. a) The experimental design applied to determine the accuracy and the reliability; b) Calibration volume used to determine the accuracy.

Table 1. Real coordinate points of the volume calibration used to determine the accuracy.

\begin{tabular}{|c|c|c|c|c|c|c|c|c|c|c|c|c|}
\hline & P1 & P2 & P3 & P4 & P5 & P6 & P7 & P8 & P9 & P10 & P11 & P12 \\
\hline$X(m)$ & 0 & 0.705 & 1.410 & 1.410 & 0.705 & 0 & 0 & 0.705 & 1.410 & 1.410 & 0.705 & 0 \\
\hline$Y(m)$ & 0 & 0 & 0 & 0 & 0 & 0 & 1.375 & 1.375 & 1.400 & 1.415 & 1.390 & 1.415 \\
\hline Z (m) & 0 & 0 & 0 & 1.415 & 1.415 & 1.415 & 0 & 0 & 0 & 1.415 & 1.415 & 1.415 \\
\hline \multicolumn{13}{|c|}{ P - Point; m - meters; } \\
\hline
\end{tabular}



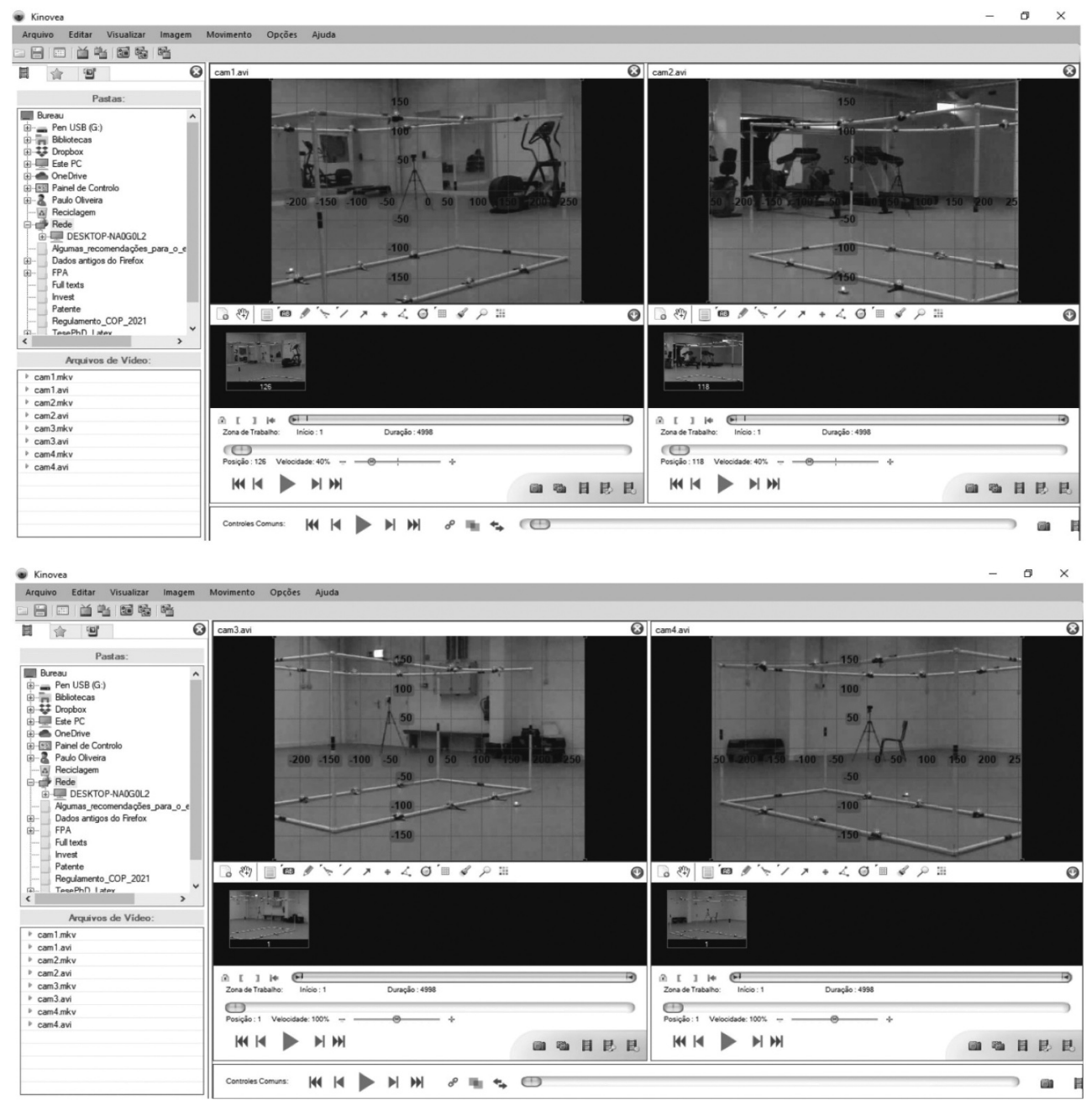

Figure 2. Snapshot from the free software analysis in the accuracy analysis.

a)

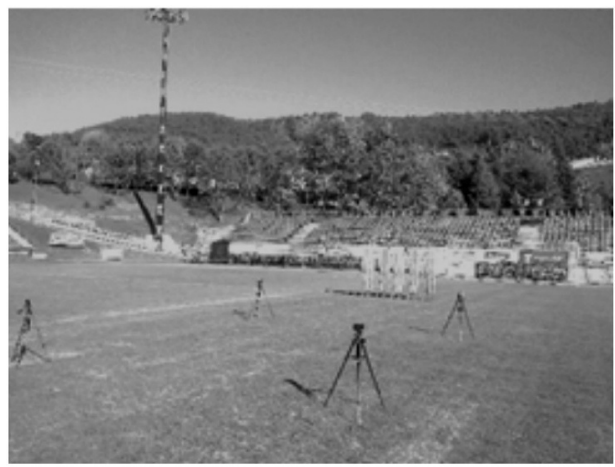

b)

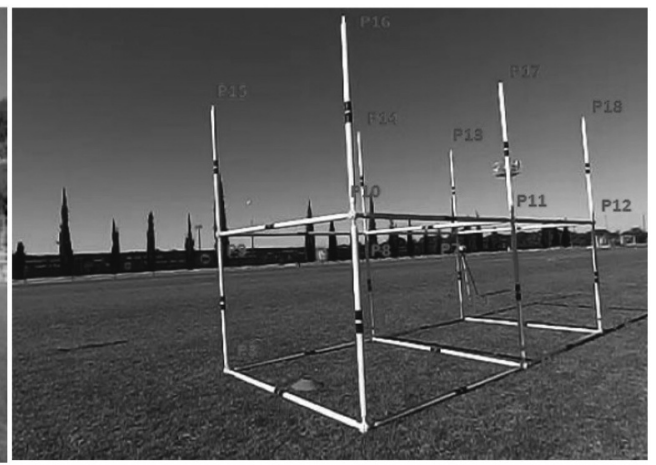

Figure 3. a) The experimental design applied in the field to determine the reliability; b) Calibration volume used to determine the reliability.

To verify the reliability, two digitalizations of the same video were performed on different days (Figure 5).

\section{Statistical analysis}

Descriptive statistical analysis was used to determine the accuracy. The mean calculation was used to describe the center of values obtained through the analysis of all frames in each software and each test. The absolute error was obtained through the difference between the real value and the mean value of each coordinate. The maximum absolute error was calculated to verify the most significant error along with all frames. The standard deviation was calculated to represent the variation or dispersion of the set of values relative to mean (Vander Linden 

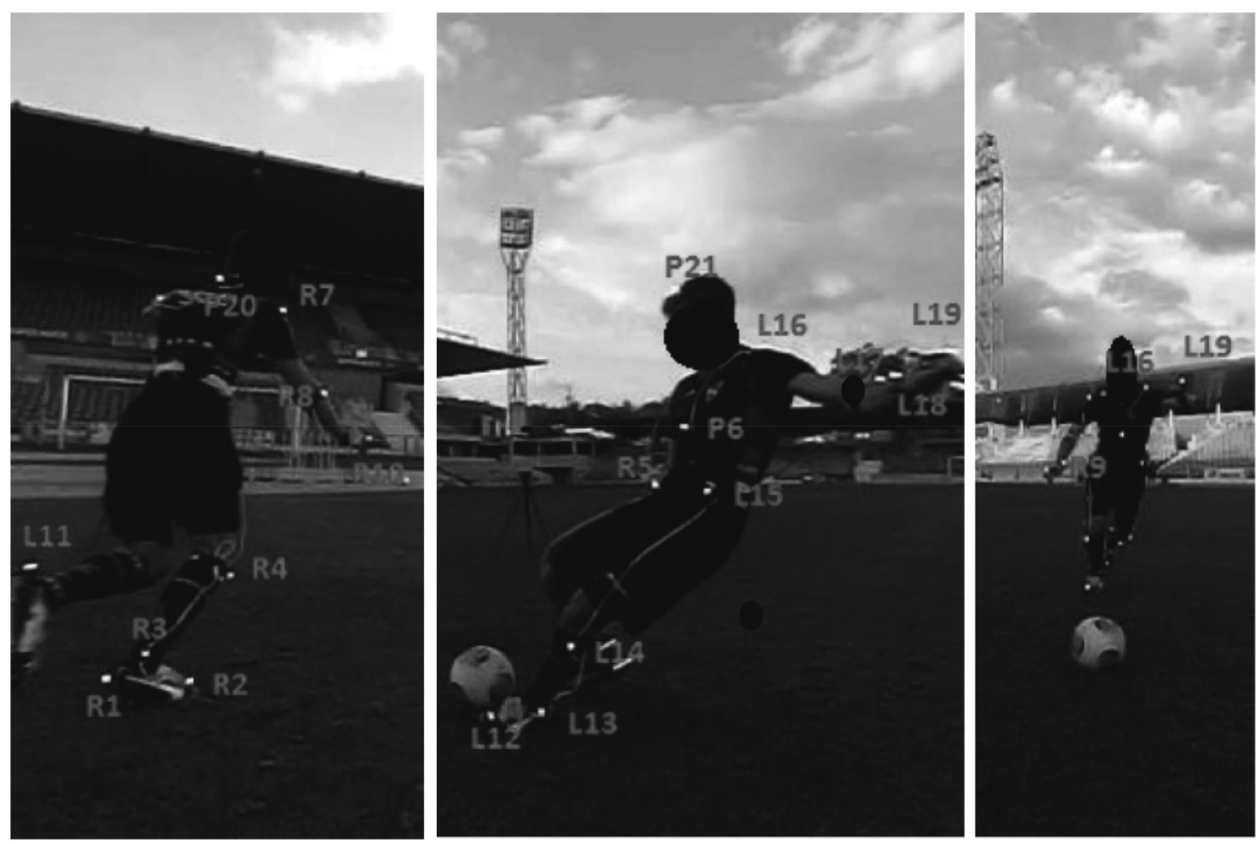

Figure 4. Collection images with the biomechanical model according De Leva (1996) recommendations.

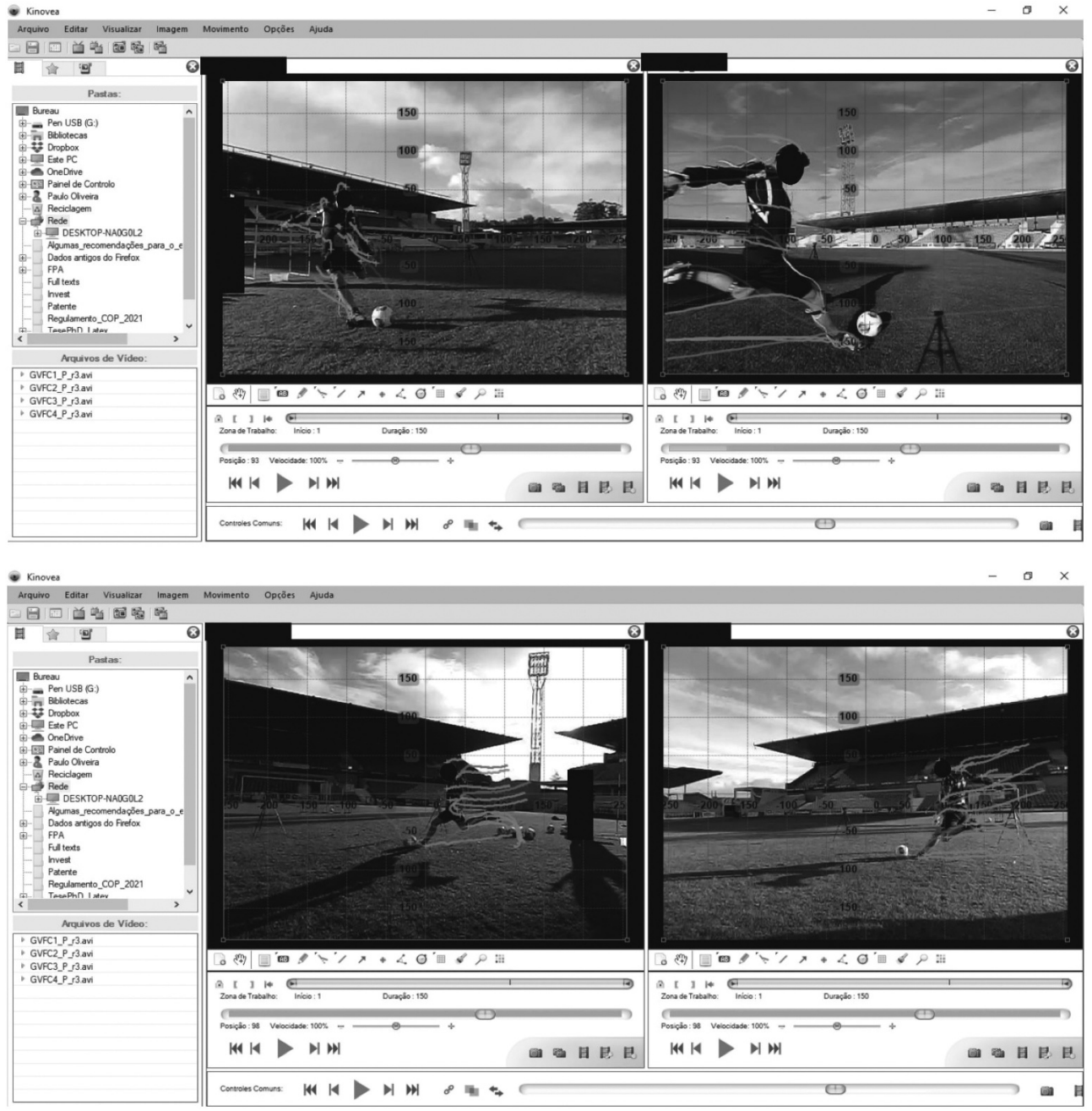

Figure 5. Snapshot from the free software analysis in the reliability analysis. 
et al. 1992; Ehara et al. 1995; Klein and DeHaven 1995; Chiari et al. 2005;). The root mean square was determined (Richards 1999).

As the motion analysis system obtains information from three-axis coordinates, the accuracy for each axis (XYZ) was also performed (Richards 1999).

To reliability was determined for each point between the two digitalization through the Intra-Classes Correlation Coefficient (ICC) (Brosseau et al. 1997; Serrano and Fernandes 2011). Semi-automatic digitalization was used in all motion analysis because, in some frames, the automatic digitalization selected the wrong landmark.

\section{Results}

All results about accuracy for the chosen software are shown in Table 2. Table 3 shows the aggregated results.

The results were obtained after the comparisons between the real coordinates of the points with the coordinate values obtained through the software. For both software and tests, the results were similar (Table 3 ).

Software 1 (Kinovea $^{\circledR}$ ) had better values in the first test. The mean absolute error for all points was $3.62 \mathrm{~mm}$ for test 1 and $3.58 \mathrm{~mm}$ for test 2 . The maximum absolute error obtained was $9.09 \mathrm{~mm}$ and $13.44 \mathrm{~mm}$ for the first and second tests, respectively. The standard deviation mean was $0.01 \mathrm{~mm}$ for the first test and $0.03 \mathrm{~mm}$ for the second test. The root mean square was equal for both tests, with a value of $0.6 \mathrm{~mm}$. The homogeneity was under $1 \%$ in both tests. In the validity test, it was possible to use automatic digitalization, and it had a duration of 16 minutes to analyze all points.

Software $2\left(\right.$ APAS $\left.^{\oplus}\right)$ had similar values for both tests when accuracy was evaluated. The mean absolute error was $3.78 \mathrm{~mm}$ for test 1 and $3.64 \mathrm{~mm}$. The maximum absolute error was smaller for the first test, with $9.12 \mathrm{~mm}$, and in the second test, the error was $11.61 \mathrm{~mm}$. The dispersion was $0,59 \mathrm{~mm}$. The root mean square was $0.63 \mathrm{~mm}$ and $0.61 \mathrm{~mm}$ for test 1 and test 2, respectively. The homogeneity was $5 \%$ in both tests. The automatic digitalization had a duration of 31 minutes when analyzed all points.

The accuracy was also calculated per axis coordinates, and Table 4 showed the results.

In general, for both softwares, the Z-axis had the smallest results (Table 4), and the $Y$-axis had the higher results (Table 4) for the two tests. The software 1 had as exceptions for the smaller values, the maximum absolute error in test 2 (X-axis $7.17 \mathrm{~mm})$, the dispersion to mean absolute error in test 2 (X-axis $-0.02 \mathrm{~mm}$ ), and the variation coefficient mean in both tests, $X$ and $Y$ axis in test $1(0 \%)$ and $X$-axis in test $2(0.272 \%)$. Although the exceptions for the higher values were the maximum absolute error in test 1 (X-axis $-9.09 \mathrm{~mm}$ ), the variation coefficient mean in both tests (Z-axis - test $1-0.26 \%$ and test $2-0.951 \%$ ) and the mean relative error in both tests (test $1-0.249 \%$ and test $2-0.254 \%$ ).

In software 2, the exceptions for the smaller values were the standard deviation to mean absolute error in both tests ( $Y$-axis in both tests $-0.51 \mathrm{~mm}$ ), the dispersion to the mean in Y-axis in both tests (test $1-5.031 \%$ and test $2-0.291$ ). The exceptions for the higher values were the dispersion to mean absolute error in both tests (Z-axis in both tests $-0.63 \mathrm{~mm}$ ), the variation coefficient mean in Z-axis in test $1(15.96 \%)$ and $X$-axis in test 2 $(22.57 \%)$, and the mean relative error in test 1 (X-axis $-0.266 \%)$.

\section{Discussion}

To determine the motion analysis systems' accuracy, we used descriptive statistical analysis to calculate the purposed parameters, according to the reviewed studies. The mean absolute error had a range of values between $3.62 \mathrm{~mm}$ and the $3.78 \mathrm{~mm}$ (Table 4); these values are similar to those found in the literature (Ehara et al. 1995; Klein and DeHaven 1995; Everaert et al. 1999; Papic et al. 2004). Klein and DeHaven (1995) obtained smaller values to $3.5 \mathrm{~mm}$. Ehara et al. (1995) between $0.9 \mathrm{~mm}$ and $6.8 \mathrm{~mm}$, and later, the range of values was between $0.94 \mathrm{~mm}$ and $18.42 \mathrm{~mm}$ (Ehara et al. 1997). Everaert et al. (1999) had values with better accuracy $(0.094 \mathrm{~mm})$. Papic et al. (2004) had values between $0.94 \mathrm{~mm}$ and $11.61 \mathrm{~mm}$. According to these papers, the software had acceptable values for the mean absolute error.

The maximum absolute error for the two software had values between $8.99 \mathrm{~mm}$ and $13.44 \mathrm{~mm}$ (Table 4); this range of values was identical to that found in the literature (Ehara et al. 1995, 1997; Papic et al. 2004). Ehara et al. (1995), Ehara et al. (1997)) had values between $0.01 \mathrm{~mm}$ and $28.23 \mathrm{~mm}$. Papic et al. (2004) show values with a similar range $(4.37 \mathrm{~mm}$ to $13.47 \mathrm{~mm}$ ).

The standard deviation average to absolute error was also determined in both digitalization's for each software, and it had values between $0.01 \mathrm{~mm}$ and $0.63 \mathrm{~mm}$ (Table 4), which were smaller than other references (Vander Linden et al. 1992; Klein and DeHaven 1995; Ehara et al. 1995, 1997; Papic et al. 2004). Vander Linden et al. (1992) had values between $1.39 \mathrm{~mm}$ and $3.04 \mathrm{~mm}$, although higher, Klein and DeHaven (1995) had values between $3.5 \mathrm{~mm}$ and $7.8 \mathrm{~mm}$. Ehara et al. (1995), Ehara et al. (1997)) obtained a range of values between $0.14 \mathrm{~mm}$ and $6 \mathrm{~mm}$, and Papic et al. (2004) obtained values between $0.39 \mathrm{~mm}$ and $5.36 \mathrm{~mm}$. Our results were smaller than those found in the literature, showing the advantage of using the abovementioned methods.

Richards (1999) indicated that the root mean square in all their analysis was smaller than $1 \mathrm{~mm}$, and in our study, the root mean square was also smaller than $1 \mathrm{~mm}$.

The literature has not verified the variation coefficient, which shows the homogeneity of the values, but when compared the homogeneity between the two software, software 1 had a smaller value than software 2 , with respectively $0.5 \%$ and $5 \%$ (Table 2); it suggests that when we use the automatic digitalization of the software 2 occurred a high variation.

The digitalization time is important to give fast results, so the time duration was determined. For the same task, both software presented different digitalization times: software 1 during half of the total time of software 2, indicating that if we need fast results, software 1 may be a good solution.

Klein and DeHaven (1995) determine the mean absolute error and the standard deviation mean of the absolute error per axes coordinates. The mean absolute error was $3.9 \mathrm{~mm}$ for $\mathrm{X}$-axis coordinates, $4.3 \mathrm{~mm}$ for $\mathrm{Y}$-axis coordinates (high value), and $2.1 \mathrm{~mm}$ for Z-axis coordinates (small value) (Klein and 


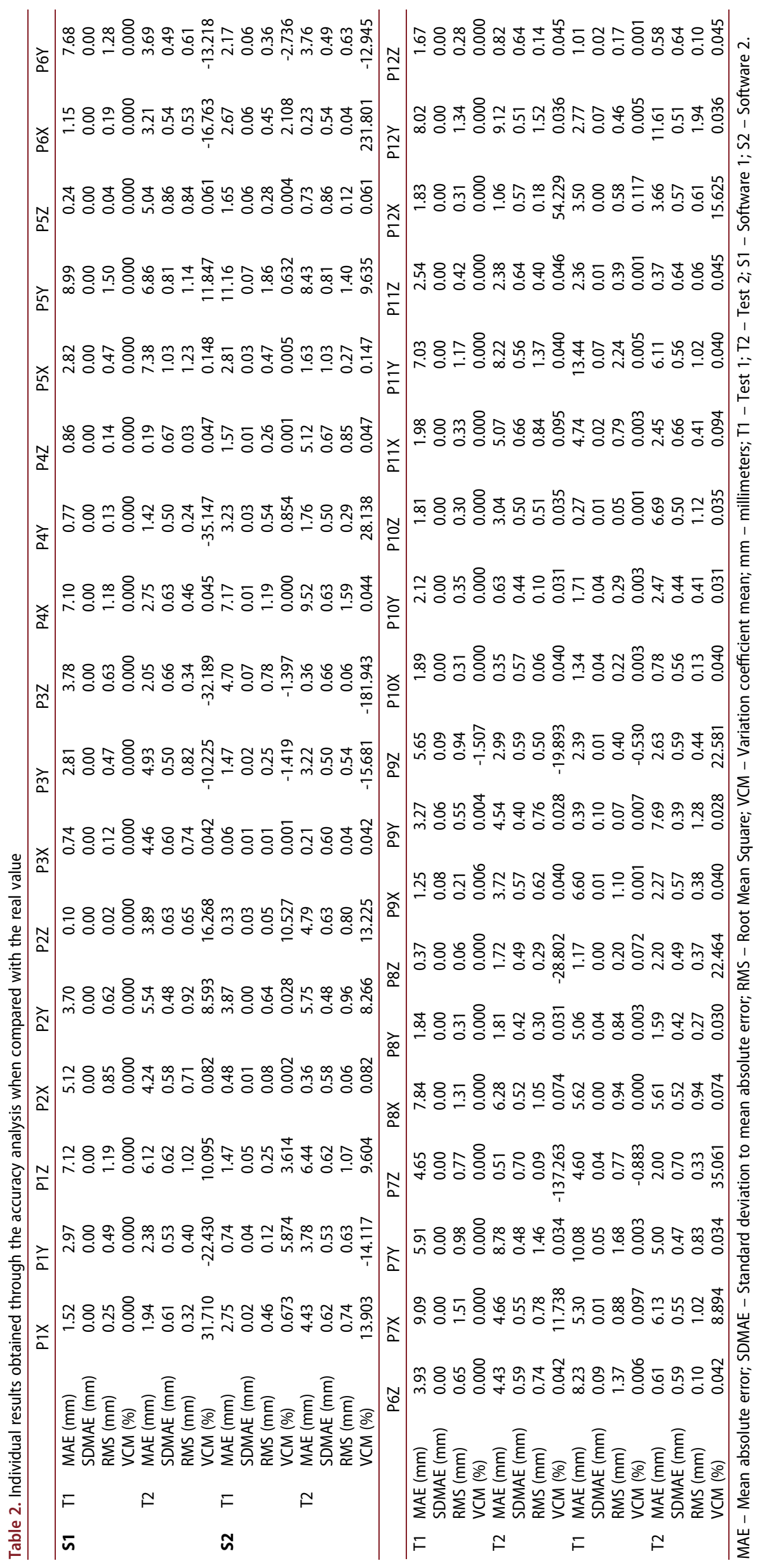


Table 3. Global results obtained through the accuracy analysis when compared with the real value.

\begin{tabular}{|c|c|c|c|c|c|c|c|}
\hline & & $\begin{array}{l}\text { MAE } \\
(\mathrm{mm})\end{array}$ & $\begin{array}{c}\text { MaxAE } \\
(\mathrm{mm})\end{array}$ & $\begin{array}{c}\text { SDMAE } \\
(\mathrm{mm})\end{array}$ & $\begin{array}{l}\text { RMS } \\
(\mathrm{mm})\end{array}$ & $\begin{array}{c}\text { VCM } \\
(\%)\end{array}$ & $\mathrm{T}(\mathrm{min})$ \\
\hline \multirow[t]{2}{*}{ S1 } & $\mathrm{T} 1$ & 3.62 & 9.09 (P7X) & 0.01 & 0.60 & 0.042 & 16 \\
\hline & $\mathrm{T} 2$ & 3.58 & $\begin{array}{l}13.44 \\
\quad(\mathrm{P} 11 \mathrm{Y})\end{array}$ & 0.03 & 0.60 & 0.491 & \\
\hline \multirow[t]{2}{*}{$\mathrm{S} 2$} & T1 & 3.78 & $9.12(\mathrm{P} 12 \mathrm{Y})$ & 0.59 & 0.63 & 4.733 & 31 \\
\hline & $\mathrm{T} 2$ & 3.64 & $\begin{array}{l}11.61 \\
\quad(P 12 Y)\end{array}$ & 0.59 & 0.61 & 5.432 & \\
\hline
\end{tabular}

MAE - Mean absolute error; MaxAE - Maximum absolute error; SDMAE Standard deviation to mean absolute error; RMS - Root Mean Square; VCM Variation coefficient mean; $\mathrm{T}$ - time; $\mathrm{mm}$ - millimeters; min - minutes; T1 - Test 1; T2 - Test 2; S1 - Software 1; S2 - Software 2.

DeHaven 1995). The standard deviation mean had values $3.6 \mathrm{~mm}$ for $\mathrm{X}$-axis coordinates (high value), $2.3 \mathrm{~mm}$ for $\mathrm{Y}$-axis coordinates, and $1.3 \mathrm{~mm}$ for Z-axis coordinates (small value) (Klein and DeHaven 1995). In this study, the mean absolute error had the same tendency for two software, small values in the Z-axis and high values in $\mathrm{Y}$-axis, although the results were slightly higher. About the standard deviation mean of absolute error, the tendency was not the same, but the results were smaller than those found by Klein and DeHaven (1995). Software 1 , in test 1 , the results were equal in three axes $(0.01 \mathrm{~mm})$, and in test 2 , the small value was on $X$-axis $(0.02 \mathrm{~mm})$, and the high value was on Y-axis $(0.05 \mathrm{~mm})$. Software 2 had small values on $Y$-axis $(0.51 \mathrm{~mm})$ and high values on the Z-axis (0.63). It suggests the importance of knowing the accuracy of the motion analysis system in different tasks, in line with Ehara et al. (1997).

Other accuracy parameters for axes coordinates were calculated, and it had, in globality, the same tendency, small values for the Z-axis and high values for Y-axis (Table 4). Although the variation coefficient (Table 4) had a higher difference when compared the two software. Software 1 obtained $0 \%$ of variability for the two tests, except in test 2 , where the Z-axis coordinates had $1 \%$, indicating a slight variation in this axis coordinates. Software 2 had higher results than software 1, except for test 2, $\mathrm{Y}$-axis coordinates had $0 \%$ of the variation; the other axis coordinates had values between $5 \%$ and $22 \%$. It suggests that occurred a higher variation in software 2 and the automatic digitalization had higher displacement in the $X$ and $Z$ axis.

The reliability was determined because semi-automatic digitalization was used for digitizing the free-kick task. The ICC was used to perform the correlation between the digitalization 1 and 2, for all points, and had a range of values, between 0.923 and 1 . These values show high intra-digitalization consistency to software proposed ( $>0.900$ ), in agreement with previous studies (Brosseau et al. 1997; Serrano and Fernandes 2011).

Technological evolution has allowed applying new biomechanical methods in sports. One of these cases is the development of new devices and software for the technical evaluation of athletes. Associated with this evolution are the high prices and the non-applicability of most of these devices in the field, which can become substantial limitations of the biomechanical studies of the technical skills in sports. Therefore, searching economical and transferable solutions and validating these methods will allow to apply this kind of study and to contribute to expanding the scientific knowledge with a broad dimension such as Soccer.

\section{Limitations}

This study had limitations, such as the low resolution of the cameras due to the use of the high-speed feature. The distance between the cameras, however, made it necessary to ensure that the full athlete's movement was recorded. The biomechanical model used did not allow analyzing some rotations. The development of the anatomical landmarks allowed a greater fixation of the points in the athlete, but due to the speed of the movement, at each shot, it was necessary to adjust the anatomical landmarks.

\section{Conclusion}

The accuracy and reliability were determined to understand the performance of a 3D camera system. The results obtained for accuracy were similar between the chosen software and the standard software and within the range of values found in the literature. The high reliability for software 1 indicates it is possible to apply this free software in the free-kick tri-dimensional kinematics analysis.

Determining the accuracy and consistency of free software is important because it is possible to apply more times this kind of system to improve the performance of motor tasks, such as the free-kick shot.

Regarding future research, the inter-digitalization calculation is recommended, and the angular kinematics protocol should be developed to analyze and validate the software purpose.

Table 4. Results per axis coordinates obtained through the accuracy analysis when compare with the real coordinate value.

\begin{tabular}{|c|c|c|c|c|c|c|c|c|c|c|}
\hline & & \multicolumn{3}{|c|}{ MAE (mm) } & \multicolumn{3}{|c|}{$\operatorname{MaxAE}(\mathrm{mm})$} & \multicolumn{3}{|c|}{ SDMAE (mm) } \\
\hline & & $x$ & Y & Z & $x$ & Y & Z & $x$ & Y & Z \\
\hline \multirow[t]{2}{*}{ S1 } & $\mathrm{T} 1$ & 3.53 & 4.59 & 2.73 & 9.09 (P7) & 8.99 (P5) & 7.12 (P1) & 0.01 & 0.01 & 0.01 \\
\hline & $\mathrm{T} 2$ & 3.59 & 4.67 & 2.48 & 7.17 (P4) & $13.44(\mathrm{P} 11)$ & $8.23(\mathrm{P} 6)$ & 0.02 & 0.05 & 0.03 \\
\hline \multirow[t]{4}{*}{ S2 } & $\mathrm{T} 1$ & 3.76 & 4.82 & 2.77 & 7.38 (P5) & 9.12 (P12) & $6.12(\mathrm{P} 1)$ & 0.62 & 0.51 & 0.63 \\
\hline & $\mathrm{T} 2$ & 3.11 & 5.10 & 2.71 & 9.52 (P4) & 11.61 (P12) & 6.69 (P10) & 0.62 & 0.51 & 0.63 \\
\hline & & \multicolumn{3}{|c|}{ RMS (mm) } & \multicolumn{3}{|c|}{ VCM (\%) } & \multicolumn{3}{|c|}{ MRE (\%) } \\
\hline & & $X$ & $Y$ & Z & $X$ & $Y$ & Z & $X$ & $Y$ & Z \\
\hline \multirow[t]{2}{*}{ S1 } & T1 & 0.59 & 0.77 & 0.45 & 0.000 & 0.000 & 0.126 & 0.249 & 0.232 & 0.096 \\
\hline & $\mathrm{T} 2$ & 0.60 & 0.78 & 0.41 & 0.251 & 0.272 & 0.951 & 0.254 & 0.236 & 0.088 \\
\hline \multirow[t]{2}{*}{ S2 } & T1 & 0.63 & 0.80 & 0.46 & 6.790 & 5.031 & 15.96 & 0.266 & 0.243 & 0.098 \\
\hline & $\mathrm{T} 2$ & 0.52 & 0.85 & 0.45 & 22.57 & 0.291 & 6.561 & 0.220 & 0.258 & 0.096 \\
\hline
\end{tabular}

MAE - Mean absolute error; MaxAE - Maximum absolute error; SDMAE - Standard deviation to mean absolute error; RMS - Root Mean Square; VCM - Variation coefficient mean; MRE - Mean Relative Error; mm - millimeters; T1 - Test 1; T2 - Test 2; S1 - Software 1; S2 - Software 2 


\section{Acknowledgments}

This research project is part of the Science and Technology Park of Alentejo - Laboratory for Research in Sports and Health (Physiology and Sports Biomechanics Unit) presented by the Sport Sciences School of Rio Maior (ESDRM) and the Health School of Santarém (ESSS) of the Polytechnic Institute of Santarém, co-financed by national funds through the Operational Program of Alentejo 2007-2013 (ALENT-07-0262-FEDER -001883), with Rita Santos Rocha as the responsible researcher.

\section{Disclosure of potential conflicts of interest}

No potential conflict of interest was reported by the author(s).

\section{Funding}

This work was supported by the Parque de Ciência e Tecnologia do Alentejo - Instituto Politécnico de Santarém - Laboratório de Investigação em Desporto e Saúde. Project coordinator is Rita Santos-Rocha [ALENT-070262-FEDER-001883].

\section{ORCID}

Paulo Miranda-Oliveira (D) http://orcid.org/0000-0002-4179-1318 Marco Branco (iD http://orcid.org/0000-0001-5238-1069 Orlando J. Fernandes (iD http://orcid.org/0000-0001-7273-8774 Rita Santos-Rocha (D) http://orcid.org/0000-0001-7188-8383

\section{References}

Abdel-Aziz YI, Karara HM, Hauck M. 2015. Direct linear transformation from comparator coordinates into object space coordinates in close-range photogrammetry*. Photogramm Eng Remote Sensing. 81(2):103-107. doi:10.14358/PERS.81.2.103.

Brosseau L, Tousignant M, Budd J, Chartier N, Duciaume L, Plamondon S, Balmer S, O'Donoghue S, Balmer S. 1997. Intratester and intertester reliability and criterion validity of the parallelogram and universal goniometers for active knee flexion in healthy subjects. Physiother Res Int. 2 (3):150-166. doi:10.1002/pri.97.

Chiari L, Croce D, Leardini U, Cappozzo A. 2005. Human movement analysis using stereophotogrammetry Part 2: instrumental errors. Gait Posture. 21(2):197-211. doi:10.1016/j.gaitpost.2004.04.004.

De Leva P. 1996. Adjustments to Zatsiorsky-Seluyanov's segment inertia parameters. J Biomech. 29(9):1223-1230. doi:10.1016/0021-9290(95)00178-6.
Ehara Y, Fujimoto H, Miyazaki S, Tanaka S, Yamamoto S. 1995. Comparison of the performance of 3D camera systems. Gait Posture. 3:166-169. doi:10.1016/0966-6362(95)99067-U

Ehara Y, Fujimoto H, Miyazaki S, YamamotoTanaka S, Yamamoto S, Yamamoto S. 1997. Comparison of the performance of 3D camera systems II. Gait Posture. 5:251-255. doi:10.1016/S0966-6362(96)01093-4

Everaert GD, Spaepen JA, Wouters JM, Stappaerts HK, Oostendorp ABR. 1999. Measuring small linear displacements with a three-dimensional video motion analysis system: determining its accuracy and precision. Arch Phys Med Rehabil. 80(9):1082-1089. doi:10.1016/S0003-9993(99) 90065-5.

Hopkins WG. 2000. Measures of reliability in sports medicine and science. Sports Med. 30(1):1-15. doi:10.2165/00007256-200030010-00001.

Jansen RG, Wiertz LF, Meyer ES, Noldus LPJJ. 2003. Reliability analysis of observational data: problems, solutions, and software implementation. Behav Res Methods Instrum Comput. 35(3):391-399. doi:10.3758/ BF03195516.

Keeley DW, Oliver GD, Dougherty CP, Torry MR. 2011. Reliability of electromagnetic tracking in describing pitching mechanics. Portuguese J Sport Sci. 29(11 (Suppl. 2)):891-894.

Klein JP, DeHaven J. 1995. Accuracy of three-dimensional linear and angular estimates obtained with the ariel performance analysis system. American Congr Rehabil Med \& American Acad Phys Med Rehabil. 76 (2):183-189. doi:10.1016/S0003-9993(95)80028-X.

Papic V, Zanchi V, Ceci M. 2004. Motion analysis system for identification of 3D human locomotion kinematics data and accuracy testing. Simul Modell Pract Theory. 12(2):159-170. doi:10.1016/j.simpat.2003.08.008.

Richards G,J. 1999. The measurement of human motion: a comparison of commercially available systems. Hum Mov Sci. 18(5):589-602. doi:10.1016/S0167-9457(99)00023-8.

Robertson, D.G., Caldwell, G.E., Hamill, J., Kamen, G., \& Whittlesey, S.N. (2014). Research Methods in Biomechanics. Champaign, IL: Human Kinetics. http://dx.doi.org/10.5040/9781492595809

Scholz J. 1989. Reliability and validity of the WATSMARTTM three-dimensional optoelectric motion analysis system. J Am Phys Ther Assoc. 69:8.

Serrano J, Fernandes O. 2011. Reliability of a new method to analyse (TACTO) to quantify the athletes displacement. Portuguese J Sport Sci. 29(11 (Suppl. 2)):935-936. https://ojs.ub.uni-konstanz.de/cpa/article/ view/4988.

Vander Linden DW, Carlson SJ, Hubbard RL. 1992. Reproducibility and accuracy of angle measurements obtained under static conditions with the motion analysis video system. Phys Ther J. 72(4):300-305. doi:10.1093/ptj/72.4.300.

Wilson A, Waters I, Motoi L, Kim E, Morgenstern M. 2012. Video analysis of chewing patterns. Proc F Bioact Process Qual \& Nutr. 1:10-12.

Wilson JD, Smith KB, Gibson K, Choe J, Gaba B, Voelz TJ. 1999. Accuracy of digitization using automated and manual methods. Phys Ther J. 79 (6):558-566. doi:10.1093/ptj/79.6.558. 